\title{
强化气象灾害防御的应急处置
}

罗瑞科 张杰 王嘉伟

广东省乐昌市气象局

DOI:10.32629/ems.v2i1.563

[摘要] 近年来, 全球气候变化不稳定的现象日益严重,这直接导致了气象灾害的频繁发生。我市位于亚热带季风 气候区域, 是气象灾害的高发地区, 易引发暴雨、高温、干旱、寒潮、雷电、台风、冰雱等灾害天气, 严重时会造成洪灾、 森林火灾、生物灾害等巨大安全事故,直接给人们的正常生产生活造成了巨大的损失,阻碍了社会经济的发展。为有 效减少气象灾害造成的损失, 有必要建立起气象灾害防御应急机制, 加强各部门的防御协调配合, 以增强灾害防御的 主动性、快速性和高效性。本文从分析我市气象灾害防御的现状出发, 提出了一些气象灾害防御的应急处置措施, 希 望可以给当前的气象灾害防御工作提供参考。

[关键词] 气象灾害防御工作; 应急机制; 措施

\section{1 气象灾害防御的现状}

1.1 防御机制得到了基本完善

气象灾害防御工作是一个地区的系统工程，它的涉 及范围特别广,需要多方面资源的配合才能顺利进行。在 这项工作的开展中需要政府的统一领导和组织, 号召全 社会成员积极地参与进来, 从而将更多有用的资源应用 到气象灾害防御中。乐昌市经过多年的探索和不断改革, 也摸索出了适合本地区的气象灾害防御机制, 即以政府 为主导,各部门(气象、水务、国土、民政、交通等)协调配 合的联动机制, 这在一定程度上加大了气象灾害防御的 工作力度, 并实现了部门行为到政府行为的转变。在市 委、市政府的领导下, 各个部门加强协调配合, 调动了社 会成员的参与积极性, 尽最大的可能减少了气象灾害的

勘察技术在岩土工程勘察中的应用, 就要不断提高施工 人员和勘察人员的综合素质和专业技能, 对其进行定期 的数字化勘查技术的培养, 加强他们对勘查工作中具体 数据信息的分析和整合,提高设计人员的综合素质。

此外, 还可以定期组织勘察人员进行实际的综合勘 察技术应用活动，不断加强他们对这项技术的掌握和应 用,分析勘查资料信息,对具体的数据信息进行处理,进而 在根本上实现综合勘察技术在岩土工程勘察中的应用, 不断地提高我国建筑事业在社会市场中的竞争力。

\section{4 结束语}

综上所述, 岩石工程要想在激烈的市场竞争中脱颖 而出, 就要根据实际的施工情况加强综合勘察技术在岩 土工程勘察中的应用,提高勘察人员的综合素质,对地质 特点进行分析,加强对具体数据信息的整合,不断提高岩 石工程的施工质量, 从而为促进建筑事业在社会中的稳 定发展打下坚实的基础。
发生。近年来, 我市接连发布了一系列气象灾害应急预案 文件, 明确规定了防御机制的管理结构以及各个部门在 这项工作中的职责和义务。当前我市共有预警信息显示 屏有 239 个、区域自动气象站有 27 个(含两个交通气象 站, 分别位于京珠北路段云岩服务区和广乐高速梅花北 服务区)、三防气象服务站有 17 个(分别位于乐昌市 17 个乡镇)、气象信息员 234 个、2015 年发布天气预警信息 共 16 万条。同时也规范了气象灾害防御的信息发布和 风险评估环节, 通过制定针对性的防御措施, 来减少气象 灾害造成的损失。

\section{2 防御模式得到了创新}

1.2.1 以人为本,减少危害

坚持把保障人民群众生命财产安全、维护经济社会

\section{[参考文献]}

[1]王茜,刘施荵,杨文彬.综合勘察技术在岩土工程 勘察中的应用研究 [J].建筑与装饰,2019,(1): $138+138$.

[2]罗贤贵.综合勘查技术在岩土工程勘查中的应用 探究[J].城市地理,2018,(8): $65+66$.

[3]吴红垒,李啸,李凯旋。综合勘查技术在岩土工程 勘查中的应用[J].世界有色金属,2018,(24):88.

[4]杜艳松.综合勘查技术在矿山复杂地质区域岩土 工程勘查中的应用分析 [J]. 世界有色金属,2019,(8): $369+370$.

[5]王瑞永,王豪.关于工程勘察中地基综合承载力的 探讨 $[C] / / 2018$ 年全国工程勘察学术大会,2018,(10): $188+189$.

[6]王凡莉.勘察技术在岩土工程勘察中的应用研究 [J].中国住宅设施,2019,(6): $1455+156$. 
稳定作为防御工作的出发点和落脚点, 最大程度地减少 气象灾害造成的危害和损失。

\subsection{2 以防为主,防抗结合}

坚持把生产安全、经济建设发展、社会和谐稳定作 为防御工作的主要目标, 预防与处置相结合, 常态与非常 态相结合, 居安思危, 常备不解; 完善工作机制, 强化防御 和应急处置的规范化、制度化和法制化，不断提高应急处 置工作的科学化水平,增强综合管理和应急处置能力。

\subsection{3 统一指挥,分级负责}

坚持在市委、市政府的统一领导下,建立健全属地为 主、分级负责、分类管理、条块结合的防御体制。各级人 民政府对处置本行政区域内气象灾害实施统一指挥和 协调, 各级人民政府行政首长为防御与应急处置工作的 第一责任人,对本地区相关工作负总责。

\subsection{4 全民动员,协同应对}

坚持公众参与、军民结合、专群结合、平战结合的原 则, 充分调动社会各界和广大人民群众的积极性和主动 性,有效发挥乡镇、社区、企事业单位、社会团体和志愿者 队伍的作用,形成功能齐全、反应灵敏、协同有序、运转高 效的处置机制。

\subsection{5 科学统筹,合理规划}

坚持因地制宜,城乡统筹,突出重点,兼顾一般,局部 利益服从全局利益; 在防灾安全的前提下,科学规划和利 用资源; 最大限度地满足生活、生产和生态用水需求, 实 现人与自然和谐相处。

\subsection{6 依靠科技,有效应对}

坚持依靠科技进步, 全面提高防御气象灾害和应急 处置工作水平, 做到全面监测、准确预报、及早预警、快速 响应、科学处置、有效应对。

\section{3 预警信息传播方式逐渐丰富}

气象灾害预警信息发布系统需要建立起完善的信 息发布制度,以充分的利用各方面的信息资源。目前已经 有很多信息平台,比如天气预报、短信气象平台、网络气 象平台、气象电子显示屏、气象微博、12121 气象电话等, 这些信息发布渠道都充分利用了现有的信息技术和网 络技术,并且信息发布准确、快速、高效。现在社会中的很 多公众场合都设有专门的气象电子显示屏, 人们可以多 方面的了解到当前甚至未来几天的气象情况, 扩大了气 象信息的覆盖面积, 从而可以更加及时的为气象灾害做 好防御工作。

\section{2 气象灾害防御应急处置措施}

2.1 制定科学、完善的社区气象灾害应急预案

我市 17 个乡镇分别建立了相应的气象灾害应急预 案, 气象灾害应急预案在制定时充分结合了社区的基本 情况和本地的气象灾害特征, 从而具有针对性的完善各 项操作和实施标准,将具体的预案细化, 按照重要性依次
处理; 充分的了解和掌握社区的管理结构,从而可以更加 清楚的制定出行动流程和应急措施，具体的分析合适的 避灾场所、转移路线和交通工具等,研究导致灾害发生的 因素和容易发生灾害的区域。这样当遇到气象灾害时,社 区的气象灾害防御部门就可以根据原先设计好的流程 一步一步开展工作。同时还需要注意,应急方案要根据气 象灾害的变化情况及时做出适当调整，以免过程中出现 不必要的差错和损失。最后还要加强对社区人员的灾害 防御宣传和培训,定期组织社区群众进行防御演练,鼓励 群众积极的参与进来, 在这个过程中熟悉和掌握防灾的 细节,以提高社区防灾应急工作的效率。

\section{2 加强农村农业气象灾害防御工作}

我市属于亚热带季风气候区域,气候特征非常明显, 很容易发生各种气象灾害, 这就给我市的农业生产带来 了巨大的威胁。近年来,我市加强了气象防御灾害预警机 制,并取得了非常不错的成效。但是在农村气象灾害防御 体系建设上还存在明显不足,仍然存在组织不健全、信息 不够畅通、防范措施差等问题。要加强农业气象灾害防 御,通过政府的统一领导,协调各部门建立起农业应急减 灾组织体系。各个乡镇都设有气象服务站,每个村都有气 象信息员。镇政府中要设立农业气象服务站,来分管气象 灾害防御工作；加强气象灾害防御业务服务体系建设。 气象部门通过建立完善灾害性天气使天气预报系统和 预警发布平台精细化,提高预报的准确率,将预报精确到 乡镇,以增强预警信息的针对性、时效性和全面覆盖性。 外还要做好气象灾害应急灾害预案和气象灾害应急准 备认证工作,加大农业农村气象防御工作的经费投人,加 强对农业气象灾害防御工作的目标责任管理等。

2.3 建立气象灾害防御应急准备工作的认证制度

要加强社区、城镇以及企业等基层部门的气象灾害 防御工作, 最重要的一步就是建立气象灾害应急准备工 作认证制度。目前, 我市已与 10 个单位建立认证制度。这 项制度可以为各基层单位建立起一套完备的气象灾害 应急准备体系, 体系中主要有各分管部门领导的工作职 责、应急处理预案以及气象预警信息的接收渠道 ${ }^{[1]}$ 。要求 必须有专门的工作场所和避灾场所，各基层单位都必须 配有防雷装置, 还要储备必须的应急物资, 广泛开展气象 防御知识宣传教育,通过志愿加人灾害防治工作的形式, 不断壮大防灾减灾的工作队伍。在基层地区和单位经常 组织开展灾害防御模范活动,政府要加强对模范单位、模 范社区的认证和考核,还要建立起必要的奖惩机制,以发 挥基层力量在防灾工作中的主观能动性。此外,气象灾害 保险也在这一过程中发挥了重要的作用, 我们要充分利 用它的优势,增加认证合格单位的保险业务范围,比如农 村养殖和种植大户、大中型的工矿企业等, 通过建立一系 列的投保和理赔措施来促进防御工作的有效开展，进而 
提升基层单位的灾害防御能力。

\section{4 加强气象灾害防御工作的知识宣传}

很多地区在开展气象灾害防御工作时都会应用到 宣传这种方法, 同时宣传也是防御工作开展中一项非常 非常关键的环节。增强了基层群众的气象灾害防御意识, 才会有效激发他们主动学习灾害防御知识的积极性,从 而提高群众整体的避灾能力和自救、互救能力。在基层 社区和农村开展防灾知识的宣传方式有很多, 比如利用 3.23 气象开放日作宣传、开展知识讲座、张贴防灾知识 图片和展板等等,宣传工作要一直进行, 才能逐渐唤起人 们的灾害防御意识。防灾意识的增强会指引人们做好灾 前的各项准备工作和避难措施。气象灾害防御部门还要 加强对居民防灾的模拟演练, 这样在灾害真正来临时, 人 们就可以根据经验有条不紊的避灾，这就大大提高了基 层社区的防灾应急工作效率，进而提高整体的灾害防御 能力。

\section{5 建立气象灾害防御多元投人机制}

气象灾害防御多元投人机制主要是指在地区的年 度规划或者中长期规划中纳人气象灾害预警、应急指 挥、信息发布等工作,并且还要将这些工作归入到地方财 政预算中 ${ }^{[2]}$ 。政府要加大对气象灾害防御工作的投人力 度, 可以通过号召鼓励企业捐助或者设立基金等形式来 筹集防灾资金，合理的运用这些资金去设立避灾场所和 设施, 储备足够的防灾物资, 以保证灾害来临时可以进行 高效率的开展避灾和应急工作。

2.6 实现气象灾害防御应急处置工作法制化

2.6.1 气象灾害防御工作的立法问题

当前社会中存在各种各样的突发性公共事件, 在这 其中自然灾害的比率最大, 且破坏性最强, 受灾面积也最 大。气象灾害是自然灾害中最常见的一种, 发生的几率比 较大, 涉及的范围较广, 造成的损害也比较大。所以地方
政府应该加强气象灾害防御应急工作。要想防灾应急工 作正常开展, 关键要加强气象灾害防御的立法工作, 以政 府为主导形成一个联动的应急机制, 做好各部门的衔接 工作,提高约束力,从上到下从而形成一个完整的体系。 立法工作是所有进程的根本基础,也是重要的法律保障, 只有做好立法工作,才能顺利的进行后续工作。

\subsection{2 加强各部门之间的应急联动机制}

气象灾害是一种突发性比较强、破坏性较大的自然 灾害,因此应急工作通常比较复杂。灾害天气的种类有很 多,预警等级也有高有低,有时需要在极短的时间内做出 应急措施,但要从根本上减轻灾害后果,还需要加强防御 机制的联动作用 [3]。这就需要政府不断加强各个部门的 协调工作, 平时多组织开展应急演练, 以提高各部门相互 配合的能力以及应急反应速度, 最大限度的减少人们群 众的生命财产损失。

\section{3 结论}

气象灾害防御的应急机制是做好一切工作的前提, 政府要不断加大投人和支持力度,强化应急工作,完善灾 害防御体系,提高抢险救灾工作能力, 有效防御气象灾害, 最大程度减少人员伤亡和财产损失; 实现防御工作规范 化、制度化、法制化,保障我市社会经济全面、协调和可持 续发展。提高这项工作的主动性和使命感, 为社会和人们 建立一道坚实的屏障。

\section{[参考文献]}

[1]何晨.试论我国气象灾害防御的应急管理 [J].内 蒙古气象,2011(06): 103+120.

[2]赵伟明.推进“两个体系”建设提升气象灾害防御 能力[J].气象研究与应用,2014(04):67+70.

[3]王志强.有效防御气象灾害的法制建设研究 [J]. 阅江学刊,2013(03):26+30. 